\title{
Metabolism of the Flavonoid Epicatechin by Laccase of Colletotrichum gloeosporioides and Its Effect on Pathogenicity on Avocado Fruits
}

\author{
R. Guetsky, I. Kobiler, X. Wang, N. Perlman, N. Gollop, G. Avila-Quezada, I. Hadar, and D. Prusky
}

\begin{abstract}
First, second, fourth, fifth, and eighth authors: Department of Postharvest Science of Fresh Produce, Institute for Technology and Storage of Agricultural Products, the Volcani Center, Agricultural Research Organization, Bet Dagan 50250; sixth author: Centro de Investigacion en Alimentación y Desarrollo A.C. Unidad Delicias, Chihuahua, México C.P. 33089, and seventh author: Department of Plant Pathology and Microbiology, Faculty of Agriculture, the Hebrew University of Jerusalem, Rehovot 74100, Israel. R. Guetsky and I. Kobiler contributed similarly to this manuscript.
\end{abstract}

Current address of X. Wang: Donald Danforth Plant Science Center, 975 N. Warson Rd., St. Louis, MO 63132.

Accepted for publication 28 June 2005.

\begin{abstract}
Guetsky, R., Kobiler, I., Wang, X., Perlman, N., Gollop, N., Avila-Quezada, G., Hadar, I., and Prusky, D. 2005. Metabolism of the flavonoid epicatechin by laccase of Colletotrichum gloeosporioides and its effect on pathogenicity on avocado fruits. Phytopathology 95:1341-1348.

During avocado fruit ripening, decreasing levels of the flavonoid epicatechin have been reported to modulate the metabolism of preformed antifungal compounds and the activation of quiescent Colletotrichum gloeosporioides infections. Epicatechin levels decreased as well when C. gloeosporioides was grown in the presence of epicatechin in culture. Extracts of laccase enzyme obtained from decayed tissue and culture media fully metabolized the epicatechin substrate within 4 and $20 \mathrm{~h}$, respectively. Purified laccase protein from $C$. gloeosporioides showed an apparent MW of 60,000, an isoelectric point at $\mathrm{pH} 3.9$, and maximal

EDTA and thioglycolic acid reduced C. gloeosporioides symptom development when applied to ripening susceptible fruits. Isolates of $C$. gloeosporioides with reduced laccase activity and no capability to metabolize epicatechin showed reduced pathogenicity on ripening fruits. On the contrary, Mexican isolates with increasing capabilities to metabolize epicatechin showed early symptoms of disease in unripe fruits. Transcript levels of cglacl, encoding C. gloeosporioides laccase, were enhanced during fungal development in the presence of epicatechin at $\mathrm{pH}$ 6.0, where avocado fruits are susceptible to fungal attack. But transcript increase was not detected at $\mathrm{pH} 5.0$, where the fruit is resistant to fungal attack. The present results suggest that biotransformation of epicatechin by $C$. gloeosporioides in ripening fruits is followed by the decline of the preformed antifungal diene compound, resulting in the activation of quiescent infections.
\end{abstract} epicatechin degradation at $\mathrm{pH}$ 5.6. Inhibitors of fungal laccase such as
The phytopathogenic fungus Colletotrichum gloeosporioides (Penz.) Penz. \& Sacc. (teleomorph: Glomerella cingulata) is an important postharvest pathogen that attacks a wide variety of tropical and subtropical fruits $(27,30,35)$. C. gloeosporioides germinates on avocado (Persea americana Miller var. drymifolia (Schltdl. \& Cham.) S.F. Blake) fruit peel and forms appressoria. The infection hyphae then penetrate into the epidermal cells of the avocado exocarp but remain quiescent until the fruit ripens (5). The resistance of unripe avocado fruit to fungal attack during quiescence has been reported to depend on the presence of preformed antifungal compounds (32) and the consequent lack of secretion of fungal pathogenicity factors occurring during quiescent infections $(34,47)$.

The level of the preformed antifungal 1-acetoxy-2-hydroxy-4oxo-heneicosa-12,15-diene (antifungal diene, AFD) is affected by the relative rates of synthesis and metabolism of the compound $(29,31)$. In unripe-resistant fruits enhanced resistance to the pathogen is characterized by the activation of synthesis of the AFD in parallel to enhanced expression of key genes of its biosynthetic pathway including $\Delta^{9}$ desaturation (17), $\Delta^{12}$ desaturation (43), and elongation (45). In ripe-susceptible fruits, however, the decline in concentration of AFD has been attributed to its metabolism through the oxidative activity of lipoxygenase (15). The

Corresponding author: D. Prusky; E-mail address: dovprusk@ volcani.agri.gov.il

DOI: 10.1094/PHYTO-95-1341

(C) 2005 The American Phytopathological Society activity of lipoxygenase is modulated by the level of its inhibitor, the flavan-3-ol-epicatechin (epicatechin) (27), a natural antioxidant that is generated in the phenylpropanoid pathway, and that declines in concentration during fruit ripening. Decline in epicatechin levels leads to increase in lipoxygenase activity, along with metabolism of the AFD $(4,32,33)$. Thus, epicatechin is an important factor that modulates avocado fruit resistance to postharvest attack.

Fungal pathogenicity may, however, not only depend on induced metabolism of natural compounds by the plant, as reported in avocado fruits (4), but pathogens might have strategies for circumventing the effects of preformed or inducible compounds (23). Some fungal pathogens can avoid exposure to antifungal compounds, and others may tolerate and even combat the toxic effects of these compounds by detoxification, and so enable fungal attack. Induced antifungal compounds may be avoided or their induction may be delayed by (i) evasion by the pathogen of the host's recognition capability (22); (ii) production of suppressors of the plant defense responses (46); (iii) detoxification of antifungal compounds (e.g., tomatinase, avenacinase, laccases, etc.) $(20,21,25,38,42)$; or (iv) use of an efflux mechanism that involves active efflux by ATP-binding cassette (ABC) transporters (14).

Laccases (p-diphenol:dioxygen oxido-reductases) are part of a larger group of multicopper enzymes, detected in several fungal species, that act on a variety of polyphenol substrates that have been implicated in a wide range of biological processes that affect fungal virulence $(3,11,20,39,43,44)$. We hypothesize that metabolism of epicatechin by laccase secreted by Colletotrichum spp. 
during the initial stages of pathogenicity leads to enhanced lipoxygenase activity, decreased level of the preformed AFD, and increased susceptibility of the fruit. Our objectives are to determine the contribution of laccase in decay development of Colletotrichum spp. in avocado fruits. In the present paper, we describe the decline in concentration of the flavonoid epicatechin by C. gloeosporioides laccase and the importance of this process for the pathogenicity of $C$. gloeosporioides in ripening avocado fruits.

\section{MATERIALS AND METHODS}

Avocado fruit, fungal isolates, growth media, fruit inoculation, and epicatechin extraction. Freshly harvested avocado fruits (cv. Fuerte) from an orchard at Kibbutz Givat Brenner, Israel were used in the experiments. A single-spore isolate of C. gloeosporioides, isolate $\mathrm{Cg}-14$, obtained from decayed avocado fruits was used in the experiments (32). Three-week-old harvested conidia from Mathur's (MS) medium plates (41) were used for conidial germination and appressorial formation assays and fruit inoculation. Conidial germination and appressorial formation were tested on glass slides and incubated at $22^{\circ} \mathrm{C}, 95 \%$ relative humidity $(\mathrm{RH})$ for $20 \mathrm{~h}$. Fruits were inoculated by placing $10 \mu \mathrm{l}$ of a conidial suspension $\left(10^{6}\right.$ conidia per $\left.\mathrm{ml}\right)$ at six longitudinally spaced inoculation spots, three on each side of the fruit. Following inoculation, fruits were incubated at $22^{\circ} \mathrm{C}, 95 \% \mathrm{RH}$ for $24 \mathrm{~h}$, in covered plastic containers containing wet paper towels; they were then transferred to ambient $\mathrm{RH}(70$ to $80 \% \mathrm{RH})$ at $22^{\circ} \mathrm{C}$ until fruit ripening and symptom development were observed (28). The average diameter of decay of 10 fruits was reported. Inoculation experiments were repeated three times.

Epicatechin was extracted from avocado pericarp ( $2 \mathrm{~g}$ of tissue, 1- to 2-mm-thick slices). Pericarp tissue was homogenized in 95\% ethanol in an Omni-Mixer (Sorvall Instruments Division, Dupont Co., Newton, CT) at full speed for 3 min. The extract was filtered through filter paper, and the ethanol sample was dried under vacuum in a Rota evaporator at $40^{\circ} \mathrm{C}$, dissolved in $10 \mathrm{ml}$ of $1 \mathrm{mM} \mathrm{NaCl}$, and fractionated twice with ethyl acetate (4). The pooled organic phases were dried with anhydrous $\mathrm{MgSO}_{4}$ and evaporated to dryness. The samples were dissolved in ethyl acetate/dichloromethane (1:3) and subjected to flush chromatography, as described previously (4). The collected samples were dried, dissolved in $1 \mathrm{ml}$ of the running solvent, and analyzed by high-performance liquid chromatography (HPLC); the column was eluted with $55 \%$ methanol and $1 \%$ acetic acid in doubledistilled water. Each experiment was run in four replicates. The epicatechin levels were calculated by comparison with a commercial epicatechin standard ([2R,3S]-2-[3,4-dihydroxyphenyl]-3,4dihydro-1[2H]-benzopyran-3,5,7-triol) (Sigma, Jerusalem, Israel). Concentrations were expressed as micrograms per gram fresh weight of fruit peel. The experiments were carried out during two consecutive harvesting seasons and repeated twice in each season. The results corresponding to one representative experiment are presented.

C. gloeosporioides laccase: purification, characterization, activity, and inhibition. Purification of laccase secreted to the culture media by $C$. gloeosporioides was carried out following the inoculation of spores $\left(1 \times 10^{6}\right.$ spores per flask) into $40 \mathrm{ml}$ of MS medium (40) at pH 5.0 according to Yakoby et al. (47) (primary growth culture). Cultures were incubated at $25^{\circ} \mathrm{C}$ in a shaking incubator at $150 \mathrm{rpm}$ for 5 days. The culture was harvested by filtration in a sterile Büchner funnel fitted with a filter paper, and the hyphae remaining on the filter were washed twice with $40 \mathrm{ml}$ of sterile distilled water. The washed mycelia were resuspended in $50 \mathrm{ml}$ of fresh medium (secondary growth culture or laccaseinducing medium) containing, per liter, $10 \mathrm{~g}$ of $\mathrm{KH}_{2} \mathrm{PO}_{4}, 5 \mathrm{~g}$ of $\mathrm{MgSO}_{4} \cdot 7 \mathrm{H}_{2} \mathrm{O}, 12.5 \mathrm{~g}$ of $\mathrm{KNO}_{3}, 0.75 \mathrm{~g}$ of $\mathrm{CaCl}_{2} \cdot 2 \mathrm{H}_{2} \mathrm{O}, 0.025 \mathrm{~g}$ of $\mathrm{FeCl}_{3}, 25 \mathrm{~g}$ of glucose, and $5.5 \mathrm{mg}$ of epicatechin. Twenty-nine hours after transfer to the inducing medium, the hyphae were filtered through a 0.45 - $\mu \mathrm{m}$-pore-size membrane filter (Supor-450; Gelman Sciences, Ann Arbor, MI). The filtrate was further concentrated four- to fivefold by ultrafiltration at $4{ }^{\circ} \mathrm{C}$ through a cellulose ester membrane (Filtron Technology Corp., Northborough, MA) with a 10-kDa cutoff (Amicon Rotterdam, The Netherlands). In some experiments the fungus was grown in $50 \mathrm{ml}$ of the minimal medium, and the medium was concentrated 10-fold in a rotary evaporator as described above.

Extraction of laccase from $C$. gloeosporioides mycelia was carried out after growing the fungus in inducing liquid media containing epicatechin. Mycelia (2.0 g fresh weight) were grounded in liquid $\mathrm{N}_{2}$ and the enzyme was extracted by mixing thoroughly with $3 \mathrm{ml}$ of $0.2 \mathrm{M}$ phosphate buffer, at $\mathrm{pH} 6.0$, containing $1 \%$ insoluble polyvinyl pyrrolidone (PVP) (Sigma, St. Louis). The slurry was centrifuged at $10,000 \times g$ for $10 \mathrm{~min}$ at $4^{\circ} \mathrm{C}$ and the supernatant was used as an enzyme source.

For extraction of laccase from avocado tissue, $5 \mathrm{~g}$ of decayed pericarp was ground with a mortar and pestle in the presence of liquid nitrogen. The enzymes were extracted by adding $5 \mathrm{ml}$ of phosphate buffer $(0.2 \mathrm{M}, \mathrm{pH} 6.0)$ containing $1 \%$ insoluble PVP. The slurry was centrifuged at $10,000 \times g$ for $10 \mathrm{~min}$ at $4{ }^{\circ} \mathrm{C}$, and $0.1 \mathrm{~g}$ of activated charcoal (Sigma, Jerusalem, Israel) was added to the supernatant. The supernatant was then mixed gently, centrifuged at $10,000 \times g$ at $4^{\circ} \mathrm{C}$, and loaded on a Sephadex G-50 Fine column (5 cm length, $1 \mathrm{~cm}$ diameter) (Amersham Pharmacia Biotech $\mathrm{AB}$, Uppsala, Sweden). The protein was eluted with $0.1 \mathrm{M}$ phosphate buffer, $\mathrm{pH}$ 6.0, and was collected in 5-ml fractions to be used as a laccase source. The concentrated products were dialyzed against 3 liters of $10 \mathrm{mM}$ sodium acetate $(\mathrm{pH}$ 6.0) and the extracts were loaded on a MonoQ anion-exchange column (Pharmacia) in a fast protein liquid chromatography (FPLC) unit (Akta, Pharmacia). Protein fractions $(1.5 \mathrm{ml}$ each) were eluted with a linear gradient of sodium acetate $(\mathrm{pH}$ 6.0) containing $1 \mathrm{M}$ $\mathrm{NaCl}$ and used for determinations of laccase activity. Protein concentrations in the samples were determined according to Bradford (6). In some experiments, partial purification of laccase was carried out with a Rotophor purification system (Bio-Rad Laboratories, Hercules, CA). Eighteen milliliters of concentrated protein extracts (approximately $1,000 \mu \mathrm{g} / \mathrm{ml}$ protein) from decayed avocado fruit extracts (as described below) or from liquid C. gloeosporioides media was separated by isoelectric focusing (IEF, Bio$\mathrm{Rad}$ ) at $15 \mathrm{~W}$ using ampholytes (Bio-Rad) in the $\mathrm{pH}$ range of 4 to 10 , according to the manufacturer's instructions.

Activity assays for laccase consisted of a reaction mixture of $100 \mu \mathrm{l}$ of $26-\mathrm{mg} / \mathrm{ml} \quad 2,2^{\prime}$-azino-bis(3-ethylbenz-thiazoline-6sulfonic acid) (ABTS) (Sigma), $800 \mu \mathrm{l}$ of $0.1 \mathrm{M}$ phosphate buffer, $\mathrm{pH}$ 6.0, and $100 \mu \mathrm{l}$ of enzyme extract in a final volume of $1 \mathrm{ml}$. The reaction was incubated at room temperature $\left(22^{\circ} \mathrm{C}\right)$, up to $60 \mathrm{~min}$, where the reaction is linear and quantified by measuring the optical density at $436 \mathrm{~nm}$ (24). Activity of laccase was also tested by analyzing by HPLC chromatography the remaining amount of phenol substrates. For that purpose, C. gloeosporioides spores were grown in primary growth culture for 5 days and then transferred for $24 \mathrm{~h}$ to a secondary growth culture containing, per liter, $10 \mathrm{~g}$ of $\mathrm{KH}_{2} \mathrm{PO}_{4}, 5 \mathrm{~g}$ of $\mathrm{MgSO}_{4} \cdot 7 \mathrm{H}_{2} \mathrm{O}, 12.5 \mathrm{~g}$ of $\mathrm{KNO}_{3}$, $0.75 \mathrm{~g}$ of $\mathrm{CaCl}_{2} \cdot 2 \mathrm{H}_{2} \mathrm{O}, 0.025 \mathrm{~g}$ of $\mathrm{FeCl}_{3}, 25 \mathrm{~g}$ of glucose, and $30 \mathrm{mg}$ of either epicatechin, DL-catechin, p-coumaric acid, or caffeic acid. In some experiments, the amount of epicatechin added was $25 \mathrm{mg} /$ liter of culture.

Optimal $\mathrm{pH}$ activity for epicatechin degradation was determined by assaying epicatechin residue following incubation of enzyme extract in the presence of $30 \mathrm{mg}$ of epicatechin per liter in $0.1 \mathrm{M}$ phosphate buffer at $\mathrm{pH}$ ranging from 4.8 to 6.2. Assay reactions at each $\mathrm{pH}$ with boiled enzyme extract were used as controls. The laccase activity enhancer $\mathrm{Cu}^{++}$was tested either by adding $\mathrm{CuSO}_{4}$ to a final concentration of $2 \mathrm{mM}$ to the reaction mixture or by growing the fungus in the inducing media amended 
with $2 \mathrm{mM} \mathrm{CuSO}_{4}$. The laccase inhibitors EDTA and thioglycolic acid were included at increasing concentrations from 1 to $25 \mathrm{mM}$ in the reaction mixture.

Inhibitors of laccase were tested for their effect in vivo on decay development. EDTA at concentrations of 20 or $50 \mathrm{mM}$ and $5 \mathrm{mM}$ thioglycolic acid solutions in $0.05 \mathrm{M}$ phosphate buffer, $\mathrm{pH} 5.0$, were infiltrated in freshly harvested avocado fruits 1 day before inoculation with $10 \mu \mathrm{l}$ of a $C$. gloeosporioides conidial suspensions containing $10^{6}$ spores per $\mathrm{ml}$. The infiltration was done by dipping one longitudinal half of the fruit in the solution, reducing the atmospheric pressure to $20 \mathrm{~mm} \mathrm{Hg}$ within $20 \mathrm{~s}$, and then releasing the vacuum. The other half of the fruit was then similarly infiltrated with water as a control (31).

Generation of a laccase probe for northern analysis. Degenerate primers corresponding to the conserved sites of several fungal laccases (2) were used to generate a probe for northern analysis. The sequence of the degenerate primers was 5'-GGAATTCTGGTAYCACAGCCACTT-3' (forward primer) and 5'-GGAATTCTCRTGGCCRTGAAGRTG-3' (reverse primer). The polymerase chain reaction (PCR) contained $100 \mathrm{ng}$ of genomic DNA of $C$. gloeosporioides and was prepared according to Yakoby et al. (47). The cycling conditions were as follows: $95^{\circ} \mathrm{C}$ for $1 \mathrm{~min}$ in 1 cycle; $94^{\circ} \mathrm{C}$ for $1 \mathrm{~min}, 58^{\circ} \mathrm{C}$ for $40 \mathrm{~s}$, and $72^{\circ} \mathrm{C}$ for $1 \mathrm{~min}$ in 35 cycles; and finally, $72^{\circ} \mathrm{C}$ for $8 \mathrm{~min}$. The PCR product was cloned into pGEM-T-Easy (Promega, Madison, WI) and purified plasmid DNA was sequenced using the universal primers for this vector. The sequence data were analyzed with the BLAST package at the National Center for Biotechnology Information (NCBI) and the nucleotide sequence was deposited as GenBank accession no. AY853696. Deduced amino acid sequence of the PCR fragment from the laccase gene of $C$. gloeosporioides was aligned to the corresponding region in the laccase of Neurospora crassa using the BioEdit program (13).

Southern blot analysis was performed according to the protocol of Amersham Pharmacia Biotech (Buckinghamshire, UK), for Hybond-N ${ }^{+}$. Genomic DNA of C. gloeosporioides $(20 \mu \mathrm{g})$ was digested with XhoI, HindIII, and EcoRI; hybridization was performed at $65^{\circ} \mathrm{C}$ with the 908-bp probe of cglacl; and the membrane was washed at high stringency. The probed membrane was exposed to Kodak BioMax MR Film (Eastman Kodak Co., Rochester, NY).

Northern blot analysis was performed following the isolation of total RNA of C. gloeosporioides with the RNeasy Plant Mini Kit (QIAGEN Sciences, Hilden, Germany). Total RNA was run in standard formaldehyde denaturing gels (36). After separation, the RNA was transferred to a Hybond- $\mathrm{N}^{+}$membrane, hybridized with a ${ }^{32} \mathrm{P}$-dCTP-labeled-cglac1 probe, and exposed to Kodak BioMax MR Film (36). Hybridization signals were quantified and the percentage intensity value of the signal was derived by subtracting background intensity and comparing to the hybridization signal from the rDNA probe, as determined with MacBAS software version 2.3 (Fujifilm, Koshing Grafic Systems, Inc., Tokyo, Japan).

Selection of $C$. gloeosporioides isolates with reduced and increased pathogenicity. Isolates of $C$. gloeosporioides showing reduced pathogenicity were isolated from a healthy part of the exocarp tissue (i.e., where no symptoms were expressed) of ripe, decayed cv. Fuerte avocado fruits, obtained from an orchard in the Tzrifim farm, Israel. Tissue samples $\left(1 \times 1 \mathrm{~mm}^{2}\right)$ were exposed to $1 \% \mathrm{Na}$ hypochlorite, washed twice in sterile water, and transferred to MS media. Single-spore cultures of Colletotrichum spp. isolated from developing colonies were confirmed as C. gloeosporioides by means of PCR with taxon-specific amplification primers that included the internal transcribed spacer 4 primer $\left(5^{\prime}-\right.$ TCCTCCGCTTATTGATATGC-3') coupled with the specific primer for $C$. gloeosporioides ( $C g$ Int) (5'-GGCCTCCCGCCTCCGGGCGG-3') (10). Conidial germination, germ tube elongation, and appressorium formation of the reduced pathogenicity
C. gloeosporioides strains were compared with the wild-type Cg14 isolate as described previously.

Single spores of $C$. gloeosporioides isolates obtained from avocado orchards in Michoacan, Mexico, showing symptoms of anthracnose in unripe or in ripening fruit were compared. Tissue samples $\left(1 \times 1 \mathrm{~mm}^{2}\right)$ were initially exposed to $1 \% \mathrm{Na}$ hypochlorite, washed twice in sterile water, and transferred to MS medium for isolation.

Data analysis. Statistical analyses of the data were performed using the JMP-in software, version 5 for Windows (SAS Institute Cary, NC). Standard errors of the means or least significant difference tests were reported.

\section{RESULTS}

Effect of C. gloeosporioides on epicatechin levels. When C. gloeosporioides hyphae were transferred from primary growth cultures to secondary growth cultures containing epicatechin, the concentration of epicatechin level declined by $50 \%$ during the first $5 \mathrm{~h}$ of incubation, and a $50 \%$ reduction of the remaining level was observed $17 \mathrm{~h}$ later (Fig. 1A). Five hours after transfer of the fungus to the secondary growth culture containing epicatechin, activity of laccase was detectable, but the highest activity (25,000 $\mu$ mol ABTS per min) was observed 45 h later (Fig. 1B). No remnants of laccase activity was detectable in mycelial extracts of C. gloeosporioides obtained from secondary growth cultures containing epicatechin.

Epicatechin levels in the pericarp of healthy cv. Fuerte avocado fruits decreased from 998 to $153 \mu \mathrm{g} \mathrm{g}^{-1}$ fresh weight during fruit ripening (Fig. 2). Epicatechin levels in the pericarp of ripe fruit decayed by $C$. gloeosporioides were only $1.5 \mu \mathrm{g} \mathrm{g}^{-1}$ fresh weight (Fig. 2) and showed a laccase activity of 22,321 $\mu \mathrm{mol}$ ABTS per
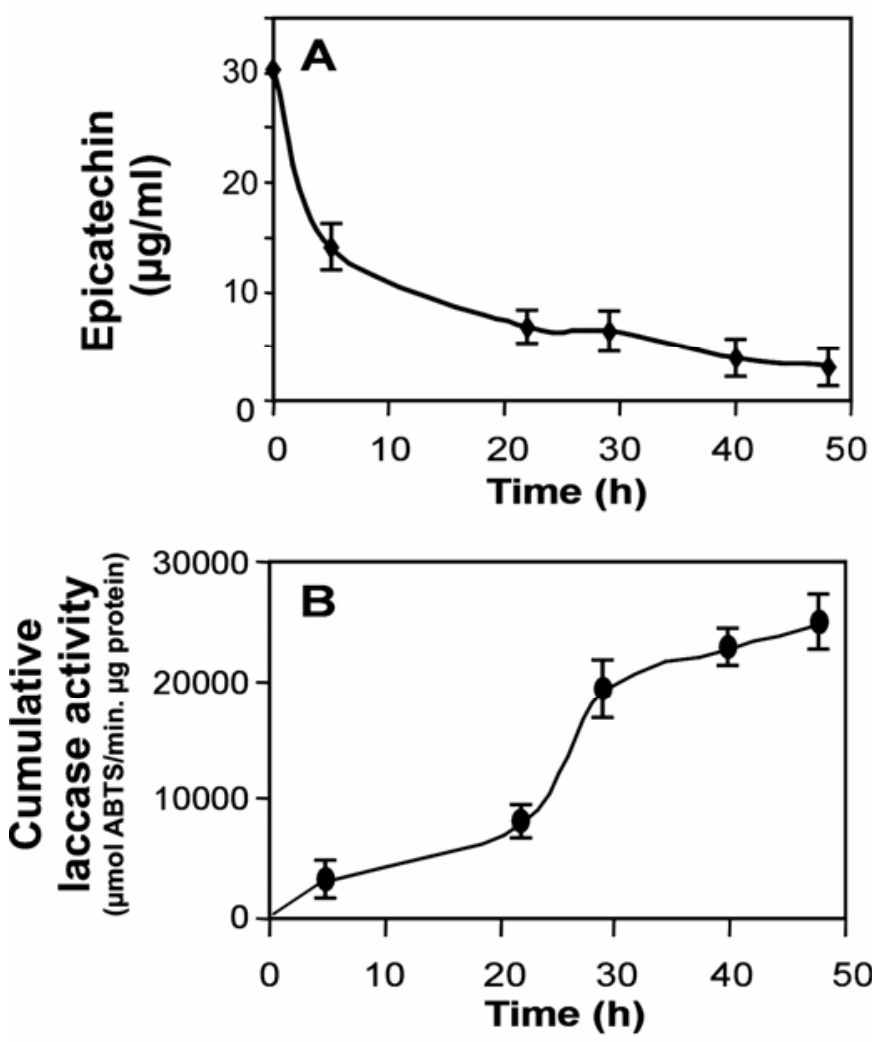

Fig. 1. Epicatechin concentrations and cumulative laccase activity in culture medium containing epicatechin at $30 \mathrm{mg} /$ liter. A, Epicatechin concentrations were measured by high-performance liquid chromatography. B, Laccase activity was measured by using 2,2'-azino-bis(3-ethylbenz-thiazoline-6-sulfonic acid) (ABTS) as a substrate. Bars represent standard error. The data from one out of three experiments with five replications per treatment are presented. 
min per $\mu \mathrm{g}$ of protein. This extract of laccase from decayed tissue reduced epicatechin concentrations in the medium by a factor of 7.5 during the first $30 \mathrm{~min}$ of incubation at $25^{\circ} \mathrm{C}$. However, extracts of healthy ripe pericarp did not contain any laccase activity and did not affect the decline in epicatechin concentration in vitro.

Characterization of laccase from $C$. gloeosporioides. Purified laccase from decayed pericarp extracts obtained by IEF or FPLC showed a single active band at $60 \mathrm{kDa}$ when the protein was analyzed by sodium dodecyl sulfate-polyacrylamide gel electrophoresis (PAGE) and compared to native PAGE with ABTS used as a developer (Fig. 3A and B). The isoelectric point of the purified protein was $\mathrm{pH} 3.9$ and the optimal $\mathrm{pH}$ for enzyme activity (from purified culture filtrates or decayed fruit extracts) was 5.4. The maximal epicatechin degradation by Colletotrichum sp. in culture was $93 \%$ of the original epicatechin content and occurred at $\mathrm{pH} 5.6$ (Fig. 4).

Secretion of laccase by $C$. gloeosporioides $21 \mathrm{~h}$ after culture inoculation was highest if epicatechin and DL-catechin were included in the medium as a substrate, whereas activities of lower intensity were obtained when p-coumaric acid or caffeic acid were used as substrates (Table 1). The residual concentrations of the nonmetabolized phenols were $12.5 \%$ for epicatechin, $1.1 \%$ for DL-catechin, and 63 and $96 \%$ for p-coumaric and caffeic acid, respectively (Table 1).

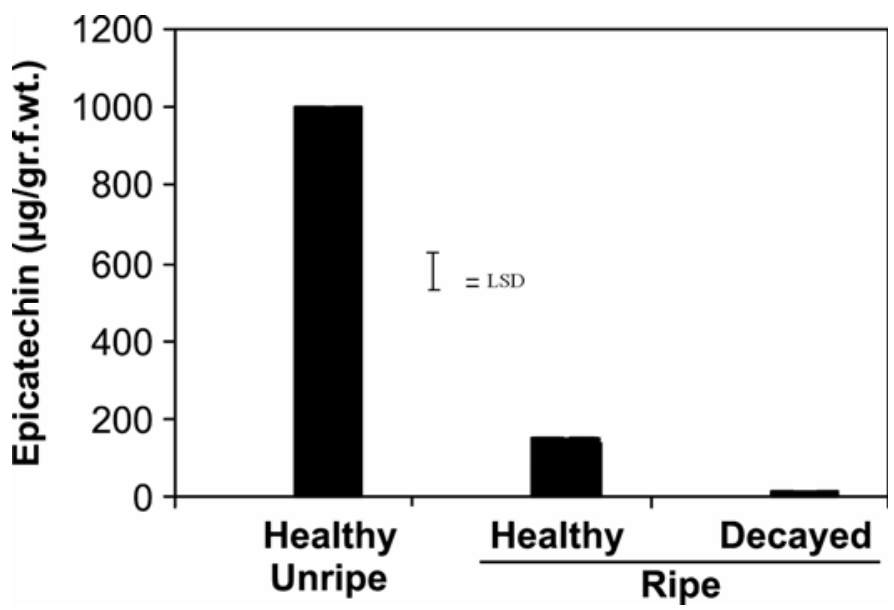

Fig. 2. Epicatechin concentrations in healthy ripe and unripe, and decayed ripe avocado fruits cv. Fuerte infected by Colletotrichum gloeosporioides. Bars represent the least significant differences (at $P \leq 0.05$ ) of epicatechin concentrations between treatments.

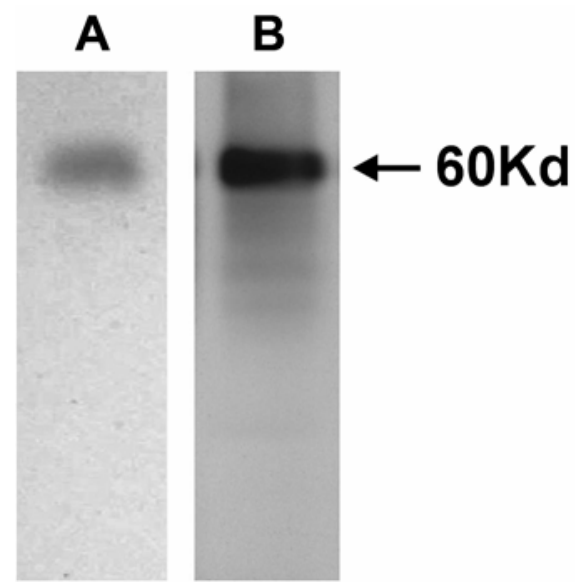

Fig. 3. Purified laccase from Colletotrichum gloeosporioides decayed pericarp extracts run in activity gel and sodium dodecyl sulfate-polyacrylamide gel electrophoresis (SDS-PAGE). A, Activity gel detected by 2,2'-azino-bis(3ethylbenz-thiazoline-6-sulfonic acid) (ABTS) (as a green color); and B, SDSPAGE gel silver stained.
Copper was also shown to activate laccase activity, as reported previously (38) for other laccases. Addition of $2 \mathrm{mM} \mathrm{CuSO}_{4}$ to the reaction mixture increased activity fourfold and a similar concentration added to the minimal growth medium increased the activity fivefold. On the other hand, laccase activity extracts from culture filtrate or from decayed fruits were inhibited by $50 \%$ in the presence of $20 \mathrm{mM}$ EDTA or $1 \mathrm{mM}$ thioglycolic acid. Infiltration of $50 \mathrm{mM}$ EDTA or $5 \mathrm{mM}$ thioglycolic acid into freshly harvested fruits reduced decay development from $7.07 \pm 0.4 \mathrm{~mm}$ in control fruits to $1.3 \pm 0.4$ and $3.5 \pm 0.6 \mathrm{~mm}$, respectively. Similar concentrations of EDTA or thioglycolic acids did not affect fungal germination or growth of $C$. gloeosporioides germ tubes.

Generation of a $C$. gloeosporioides laccase probe and northern analysis. Degenerate primers were designed in order to obtain a DNA fragment that could be used to study the expression of C. gloeosporioides laccase. The cloned PCR products were similar among themselves except that one of the clones contained a shorter fragment (data not shown). A clone of 908 bp (cglacl)

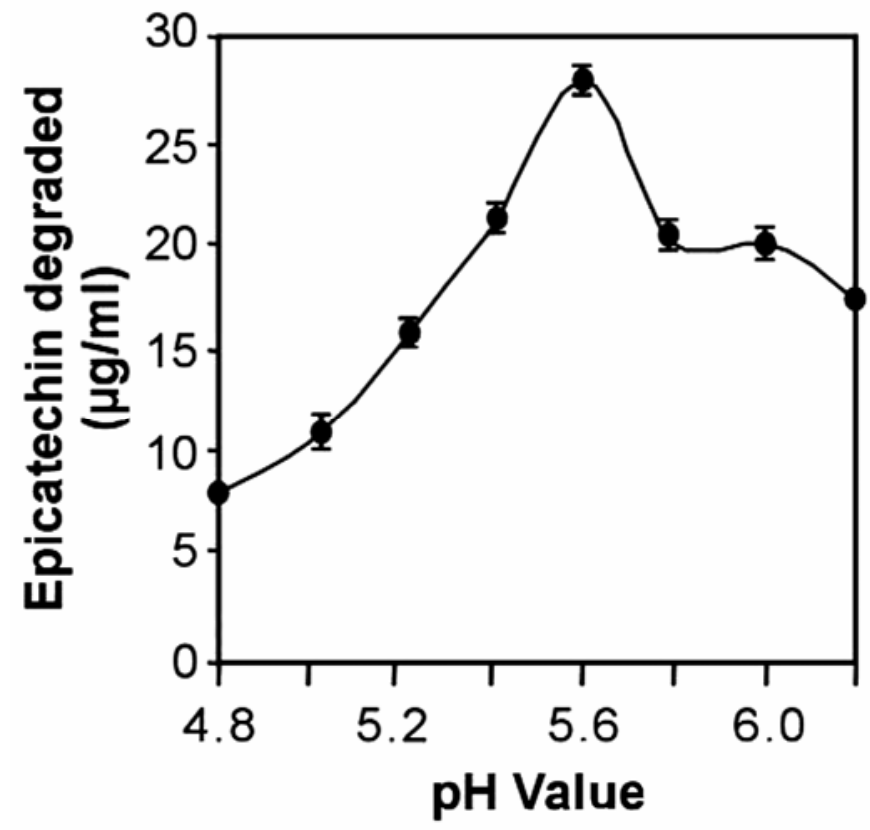

Fig. 4. Optimal $\mathrm{pH}$ for epicatechin degradation by laccase extracted from decayed avocado pericarp. Pericarp extracts were incubated at different $\mathrm{pH}$ ranges in the presence of epicatechin at $30 \mathrm{mg} / \mathrm{liter}$, and the residual epicatechin concentrations were determined after $24 \mathrm{~h}$. Bars represent standard errors. The data from one out of three experiments with five replications per treatment are presented.

TABLE 1. Laccase activity and metabolism of different phenol substrates by Colletotrichum gloeosporioides

\begin{tabular}{|c|c|c|c|}
\hline \multirow[b]{2}{*}{ Phenols substrates } & \multirow{2}{*}{$\begin{array}{c}\text { Laccase activity }^{\mathrm{a}} \\
\mu \mathrm{mole} \text { ABTS/ } \\
\text { min/ } \mu \mathrm{g} \text { of protein }\end{array}$} & \multicolumn{2}{|c|}{ Remaining phenol } \\
\hline & & $\mu \mathrm{g} / \mathrm{ml}^{\mathrm{b}}$ & $\begin{array}{c}\% \text { Initial } \\
\text { concentration }\end{array}$ \\
\hline Epicatechin & $2,082.3 \pm 229.5$ & $3.70 \pm 0.38$ & 12.5 \\
\hline DL-Catechin & $971.5 \pm 162.2$ & $0.33 \pm 0.05$ & 1.1 \\
\hline Caffeic & $176.8 \pm 32.7$ & $28.67 \pm 8.12$ & 95.8 \\
\hline Coumaric & $301.5 \pm 29.8$ & $18.86 \pm 1.85$ & 62.9 \\
\hline
\end{tabular}

a Mycelia were transferred from primary growth cultures to secondary growth cultures amended with $30 \mathrm{mg}$ of epicatechin, p-coumaric acid, DL-catechin, or caffeic acid per liter. Laccase activity was determined as described in the text following $24 \mathrm{~h}$ of growth of $C$. gloeosporioides in secondary growth culture. ABTS = 2,2'-azino-bis(3-ethylbenz-thiazoline-6-sulfonic acid). The average mean of three replications $\pm \mathrm{SE}$ is presented.

${ }^{\mathrm{b}}$ Remaining substrate concentrations after $24 \mathrm{~h}$ of growth of C. gloeosporioides in the presence of different phenol substrates. The amount of remaining substrate was determined by high-performance liquid chromatography analysis. The mean of three replications $\pm \mathrm{SE}$ is presented. 
was selected for further sequencing and it showed considerable homology to fungal laccases, including the conserved $\mathrm{Cu}$-oxidase domain of the multicopper oxidase enzymes (2). The deduced amino acid sequence of cglacl was aligned to the $N$. crassa laccase (accession no. M18333) (Fig. 5). Amino acid identity to other fungal laccases was $48 \%$ for Gaeumannomyces graminis (accession no. AJ437320) and Botryotinia fuckeliana (accession no. AF243855). Southern analysis of C. gloeosporioides genomic DNA with the 908-bp cglacl probe under high-stringency hybridization revealed one band for the XhoI digest, one main and a second minor band for the HindIII digest, and two bands of relatively low intensity for the EcoRI digest. The sequence of cglacl did not contain sites for the aforementioned restriction enzymes. Northern blot analysis yielded a single band and a relatively high basal expression of cglacl transcripts (Fig. 6). Exposure to epicatechin at $\mathrm{pH} 4.0$ did not enhance cglacl expression. However, cglacl transcripts accumulated in the presence of epicatechin as the $\mathrm{pH}$ increased from 4.0 to 5.6 (Fig. 6).

Effect of differential pathogenicity isolates of $C$. gloeosporioides on epicatechin metabolism. Of 30 isolates of C. gloeosporioides obtained from healthy, ripe, avocado tissue, only two isolates, $\mathrm{Cg}-\mathrm{W} 7$ and $\mathrm{Cg}-\mathrm{W} 10$, showed no decay development when symptoms of decay of the wild-type $C$. gloeosporioides $\mathrm{Cg}$ 14 isolate were expressed (Fig. 7). Symptoms of decay of the reduced pathogenicity isolates occurred 6 to 7 days later and only to a minor extent. Reduced pathogenic isolates did not differ from the wild type in germination rates, germ tube elongation, or appressorium formation on fruit exocarp. However, the laccase activity in culture media $36 \mathrm{~h}$ after inoculation with reduced pathogenic isolates was only $20 \%$ of that produced by the wild type, Cg-14 $(9,242 \pm 21$ in the reduced pathogenic compared with $57,137 \pm 230 \mu \mathrm{mol}$ ABTS per min per $\mu \mathrm{g}$ of protein in the wild type) (Fig. 8). During the same period, the wild-type C. gloeosporioides metabolized $96 \%$ of the epicatechin substrate, whereas the reduced pathogenic isolates reduced the epicatechin concentration by only 8 to $15 \%$ of its initial value (Fig. 8).

Mexican isolates CgM-3 and CgM-6, showing early symptoms of anthracnose in unripe fruits, could metabolize epicatechin almost twofold faster than isolates CgM-4 and CgM-5, which cause anthracnose symptoms on ripe fruit only (Table 2).

\section{DISCUSSION}

Decrease in the level of the preformed AFD was suggested as the main factor modulating quiescence of $C$. gloeosporioides during ripening of avocado fruits. Factors modulating the metabolism of preformed compounds such as plant lipoxygenase and epicatechin, an inhibitor of lipoxygenase activity, modulate the quiescent period (33). Faster epicatechin metabolism during ripening of avocado fruits increased susceptibility to decay development by $C$. gloeosporioides and shortened the quiescent period $(4,33)$. The capability of $C$. gloeosporioides laccases to reduce epicatechin concentration in the decayed tissue suggests that laccase secretion by $C$. gloeosporioides may be a factor contributing to the activation of quiescent infections $(11,43)$. Laccases are multicopper oxidases that are widely distributed among fungi involved in the biotransformation of polyaromatic compounds (16, 22). This biotransformation may lead C. gloeosporioides laccase to transform epicatechin into a product with reduced inhibition of avocado lipoxygenase.

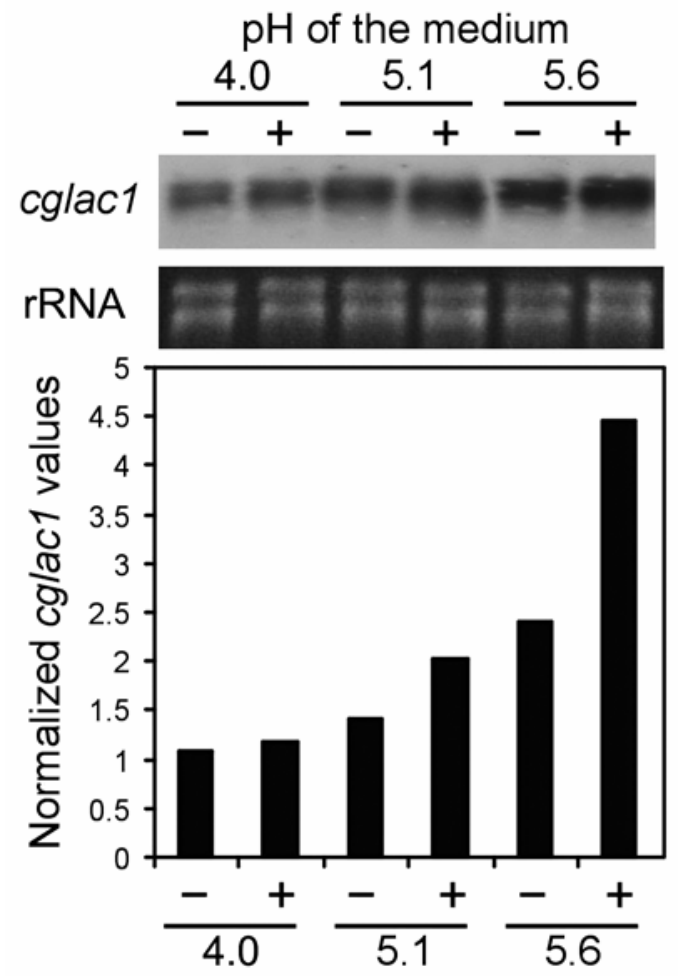

Fig. 6. cglacl transcript accumulation from Colletotrichum gloeosporioides in response to different ambient $\mathrm{pH}$ conditions in the presence and absence of epicatechin. Northern analysis of total RNA isolated from C. gloeosporioides mycelia $(20 \mu$ g loaded) after 3 days of growth in media with and without epicatechin, at the indicated $\mathrm{pH}$ values. The blot was hybridized with the 982-bp cglacl probe under high-stringency hybridization and with a ribosomal DNA (rDNA) fragment. The columns at the bottom indicate the corrected percent intensity value of cglacl based on the background intensity and the hybridization signal from the rDNA probe, as determined with MacBAS software version 2.3 (Fujifilm, Tokyo).

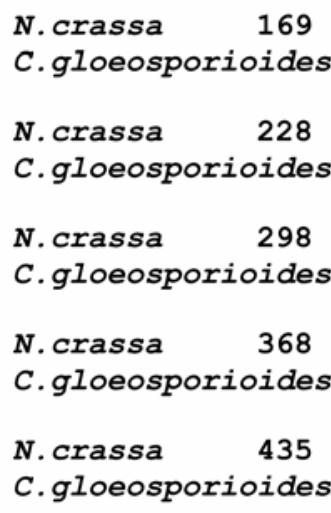

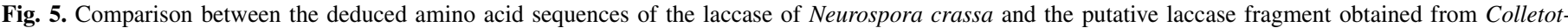

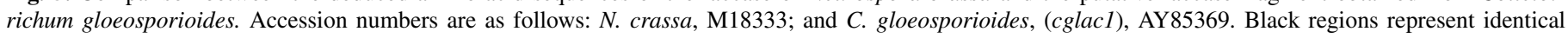
amino acid sequence and shaded regions represent similarity (7). 


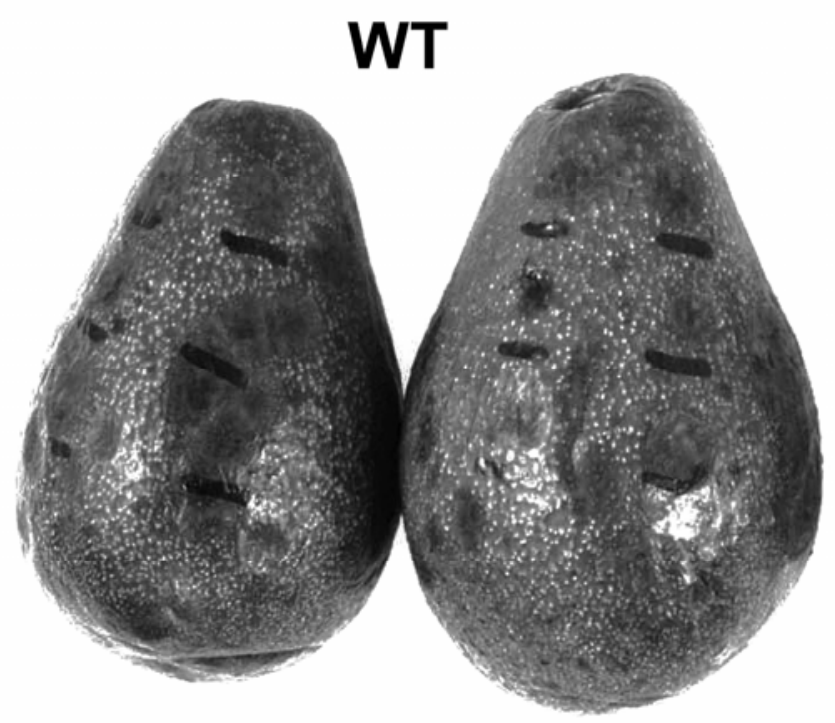

\section{Laccase reduced isolates}

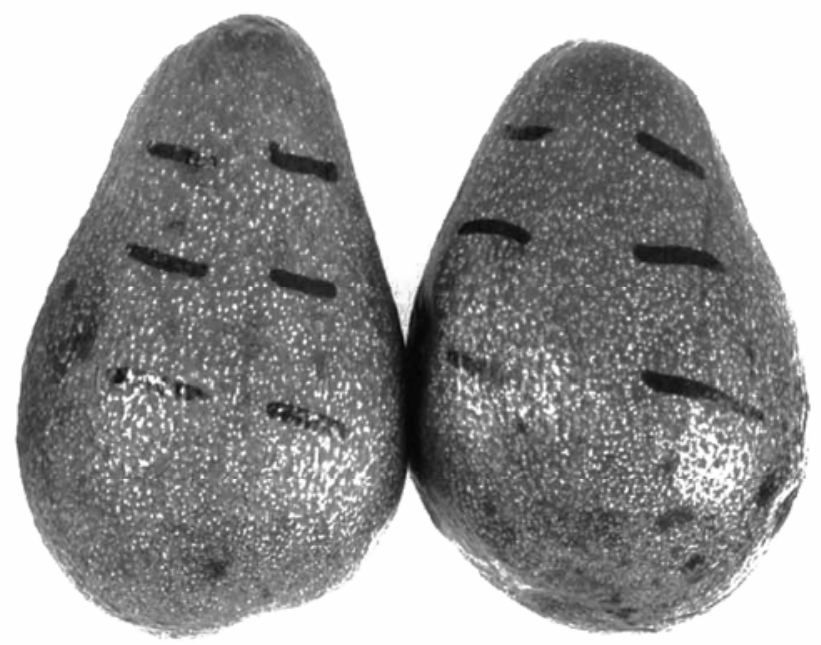

Fig. 7. Decay development by Colletotrichum gloeosporioides isolates with laccase reduced activity (isolate Cg-W7) in comparison with the wild-type isolate $\mathrm{Cg}-14$.

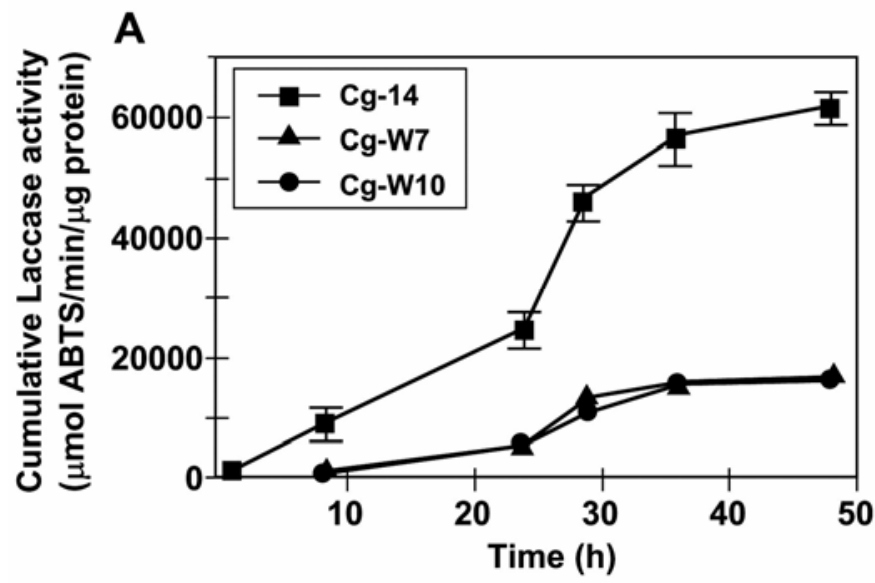

B

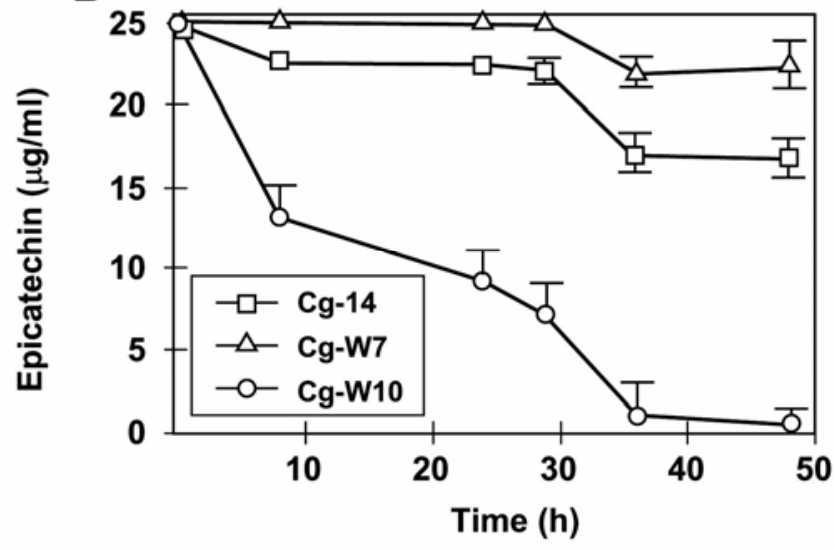

Fig. 8. Effect of reduced pathogenicity Colletotrichum gloeosporioides isolates $\mathrm{Cg}-\mathrm{W} 7$ and $\mathrm{Cg}-\mathrm{W} 10$ on laccase activity and epicatechin metabolism in comparison to wild-type $\mathrm{Cg}-14$ isolate. A, Cumulative laccase activity in culture media. Laccase activity was measured by using 2,2'-azino-bis(3ethylbenz-thiazoline-6-sulfonic acid) as a substrate. B, Epicatechin metabolism in culture medium containing epicatechin at $25 \mathrm{mg} /$ liter. Epicatechin concentrations were determined by extraction of the residual concentrations from inoculated culture media after various intervals, and detected by highperformance liquid chromatography. Bars represent the least significant differences (at $P \leq 0.05$ ) between epicatechin metabolism and laccase activity between the wild-type strain and the reduced pathogenicity isolates.
TABLE 2. Metabolism of epicatechin by Mexican isolates of Colletotrichum gloeosporioides with symptoms of disease expressed during the period of avocado fruit development or after fruit harvesting and ripening

\begin{tabular}{llccc}
\hline & & & \multicolumn{2}{c}{$\begin{array}{c}\text { Epicatechin metabolized } \\
\text { after 24 } \mathrm{h}^{\mathrm{a}}\end{array}$} \\
\cline { 3 - 5 } Isolate & Cultivar & Stage of attack & $\mu \mathrm{g} / \mathrm{ml}$ & $\%$ \\
\hline CgM-3 & Fuerte & Young fruits & $21.2 \pm 1.7$ & 84.9 \\
CgM-6 & Hass & Young fruits & $17.4 \pm 0.9$ & 69.4 \\
CgM-4 & Criollo & Ripe fruits & $7.5 \pm 1.0$ & 30.1 \\
CgM-5 & Hass & Ripe fruits & $9.2 \pm 0.1$ & 36.8 \\
\hline
\end{tabular}

a Mycelia were transferred from primary growth cultures to secondary growth cultures amended with $25 \mathrm{mg}$ of epicatechin per liter and after $24 \mathrm{~h}$ the remaining concentrations of epicatechin were detected by high-performance liquid chromatography. The average mean of three replications $\pm \mathrm{SE}$ is presented.

Purified laccase from $C$. gloeosporioides showed a molecular mass of $60 \mathrm{kDa}$, a size similar to laccase isoenzymes produced by Pleurotus eryngii, with apparent molecular masses of 56 and $70 \mathrm{kDa}$ (24), and by Fomes lignosus, with an apparent molecular mass of $66.5 \mathrm{kDa}(13)$. Gaeumannomyces graminis var. tritici, however, produced a laccase with a higher molecular mass $(190 \mathrm{kDa})$ but yielded two subunits with molecular masses of $60 \mathrm{kDa}$ when denatured and deglycosylated (9).

The optimum $\mathrm{pH}$ for laccase production by $C$. gloeosporioides, in culture or extracted from decayed fruits, was found to be 5.4, which is similar to that for laccases of the wood-degrading fungus Pleurotus pulmonarius when ABTS was used as a substrate (8). The activity of Colletotrichum laccase was also affected by the presence of copper (39). The addition of $2 \mathrm{mM} \mathrm{CuSO}_{4}$ to the culture medium or to the assay mixture increased the activity four- or fivefold. C. gloeosporioides, similarly to the ectomycorrhizal fungus Suillus granulatus (12), was able to metabolize several different phenolic compounds that are substrates for $\mathrm{Col}$ letotrichum laccase. Colletotrichum laccase reduced the concentration of catechin and epicatechin efficiently (98.9 and $87.5 \%$, respectively), and coumaric acid less efficiently (37\%), but could only marginally metabolize caffeic acid. It is possible that this substrate specificity may contribute to the differential host range of Colletotrichum spp.

Fungal laccases play a significant role in plant pathogenicity by detoxification of antifungal compounds and tannins in the host 
environment $(1,19,26,37)$. In C. gloeosporioides, a series of experiments suggest the involvement of fungal laccase in the activation of quiescent infections: (i) secretion of laccase was detected during fruit decay development accompanied by highest laccase activity; (ii) purified laccase from decayed tissue rapidly metabolized epicatechin in vitro, while no laccase activity was detected in healthy fruits; (iii) inhibition of laccase by EDTA and thioglycolic acid blocked decay development in avocado fruits, similar to the effect reported for laccase from Pleurotus eryngii (24); and (iv) C. gloeosporioides isolates that showed reduced capability to metabolize epicatechin were not able to colonize ripe fruits. On the contrary, Mexican isolates that metabolized epicatechin more rapidly showed early decay symptoms in unripe fruits. The mechanism underlying the differential secretion of laccases by the pathogenic versus the reduced pathogenicity isolates remains unknown.

The DNA fragment that was isolated by degenerate primer PCR was clearly related to fungal laccases $(9,18,40,45)$. Southern blot of $C$. gloeosporioides DNA suggested one and possibly two sequences with homology to the cglacl probe. It should be noted that two laccase genes were identified in $B$. cinerea and the difference in their DNA sequence and function was substantial (38).

Interestingly, the enzyme activity as determined by the metabolism of epicatechin by $C$. gloeosporioides was highest at $\mathrm{pH} 5.4$ and the level of transcript expression of cglacl in the presence of epicatechin increased as the $\mathrm{pH}$ increased from 5.1 to 5.6. This effect of $\mathrm{pH}$ increase on the enhancement of transcript expression of $c$ glacl was similar to that reported for $p e l B$ encoding pectate lyase from $C$. gloeosporioides (47). This would imply that the alkalinization that results from fruit ripening and ammonia accumulation by $C$. gloeosporioides (34) induced the activation of cglacl expression, its secretion, and the consequent degradation of the flavonoid epicatechin. All these results, taken together, support the importance of laccase activity as a factor that induces susceptibility in ripening fruits by modulating the level of epicatechin, the decline of the AFD, and consequently, the activation of quiescent infections by $C$. gloeosporioides in ripening fruits.

\section{ACKNOWLEDGMENTS}

We thank S. Freeman for the use of C. gloeosporioides primers, L. Persky and K. Haddad for their help in using FPLC, and Z. Charat of Kibbutz Givat Brenner for supplying avocado fruits.

\section{LITERATURE CITED}

1. Adrian, M., Rajaei, H., Jeandet, P., Veneau, J., and Bessis, R. 1998. Resveratrol oxidation in Botrytis cinerea conidia. Phytopathology 88:472476.

2. Altschul, S. F., Gish, W., Miller, W., Myers, E. W., and Lipman, D. J. 1990. Basic local alignment search tool. J. Mol. Biol. 215:403-410.

3. Anderson, D. W., and Nicholson, R. L. 1996. Characterization of a laccase in the conidial mucilage of Colletotrichum graminicola. Mycologia 88:996-1002.

4. Ardi, R., Kobiler, I., Keen, N. T., and Prusky, D. 1998. Involvement of epicatechin biosynthesis in the resistance of avocado fruits to postharvest decay. Physiol. Mol. Plant Pathol. 53:269-285.

5. Binyamini, N., and Schiffmann-Nadel, M. 1972. Latent infection in avocado fruit due to Colletotrichum gloeosporioides. Phytopathology 62:592-594.

6. Bradford, M. M. 1976. A rapid and sensitive method for the quantitation of microgram quantities of protein utilizing the principle of protein-dye binding. Anal. Biochem. 72:248-254.

7. Corpet, F. 1998. Multiple sequence alignment with hierarchical clustering. Nucleic Acids Res. 16:10881-10890.

8. De Souza, C. G. M., and Peralta, R. M. 2003. Purification and characterization of the main laccase produced by the white-rot fungus Pleurotus pulmonarius on wheat bran solid state medium. J. Basic Microbiol. 43:278-286.

9. Edens, W. A., Goins, T. Q., Dooley, D., and Henson, J. M. 1999. Purification and characterization of a secreted laccase of Gaeumannomyces graminis var. tritici. Appl. Environ. Microbiol. 65:3071-3074.
10. Freeman, S., Minz, D., Jurkevitch, E., Maymon, M., and Shabi, E. 2000. Molecular analyses of Colletotrichum species from almond and other fruits. Phytopathology 90:608-614.

11. Gonen, L., Viterbo, A., Cantone, F., Staples, R. C., and Mayer, A. M. 1996. Effect of cucurbitacins on mRNA coding for laccase in Botrytis cinerea. Phytochemistry 42:321-324.

12. Gunther, H., Perner, B., and Gramss, G. 1998. Activities of phenoloxidizing enzymes of ectomycorrhiza fungi in axenic culture and in symbiosis with Scots-pine (Pinus sylvestris L.). J. Basic Microbiol. 38:197-206

13. Hall, T. A. 1999. BioEdit: A user-friendly biological sequence alignment editor and analysis program for Windows 95/98/NT. Nucleic Acids Symp. Ser. 41:95-98.

14. Jones, P. M., and George, A. M. 2004. The ABC transporter structure and mechanism: Perspectives on recent research. Cell. Mol. Life Sci. 61:682699.

15. Karni, L., Prusky, D., Kobiler, I., Bar-Shira, E., and Kobiler, D. 1989. Involvement of epicatechin in the regulation of lipoxygenase activity during activation of quiescent Colletotrichum gloeosporioides infections of ripening avocado fruits. Physiol. Mol. Plant Pathol. 35:367-374.

16. Kurisawa, M., Chung, J. E., Uyama, H., and Kobayashi, S. 2003. Laccase-catalyzed synthesis and antioxidant property of poly(catechin). Macromol. Biosci. 3:758-764.

17. Liu, W., Chao, Y., Liu, S., Bao, H., and Qian, S. 2003. Molecular cloning and characterization of a laccase gene from the basidiomycete Fomes lignosus and expression in Pichia pastoris. Appl. Microbiol. Biotech. 63:174-181.

18. Madi, L., Wang, X., Kobiler, I., Lichter, A., and Prusky, D. 2003. Stresses regulate $\Delta^{9}$-stearoyl ACP desaturase expression, fatty acid composition, antifungal diene level and resistance to Colletotrichum gloeosporioides attack. Physiol. Mol. Plant Pathol. 62:277-283.

19. Marbach, I., Harel, E., and Mayer, A. M. 1984. Molecular properties of extracellular Botrytis cinerea laccase. Phytochemistry 23:2713-2717.

20. Mathews, D. E., and Van Etten, H. D. 1983. Detoxification of the phytoalexin pisatin by a fungal cytochrome P-450. Arch. Biochem. Biophys. 224:494-505.

21. Mayer, A. M., and Staples, R. C. 2002. Laccase: New functions for an old enzyme. Phytochemistry 60:551-565.

22. Messerschmidt, A. 1997. Multi-Copper Oxidases. World Scientific, Singapore.

23. Morrisey, J. P., and Osbourn, A. E. 1999. Fungal resistance to plant antibiotics as a mechanism to pathogenesis. Microbiol. Mol. Biol. Rev. 63:708-724.

24. Munoz, C., Guillen, A., Martinez, A. T., and Martinez, M. J. 1997. Laccase isoenzymes of Pleurotus eryngii: Characterization, catalytic properties, and participation in activation of molecular oxygen and $\mathrm{Mn}^{+2}$ oxidation. Appl. Environ. Microbiol. 63:2166-2174.

25. Osbourn, A. E. 1996. Saponins and plant defense-A soap story. Trends Plant Sci. 1:4-9.

26. Pezet, R., Pont, V., and Hoangvan, K. 1991. Evidence for oxidative detoxification of pterostilbene and resveratrol by a laccase-like stilbene oxidase produced by Botrytis cinerea. Physiol. Mol. Plant Pathol. 39:441450.

27. Prusky, D. 1996. Pathogen quiescence in postharvest diseases. Annu. Rev. Phytopathol. 34:413-434.

28. Prusky, D., Freeman, S., Rodriguez, R. J., and Keen, N. T. 1994. A nonpathogenic mutant strain of Colletotrichum magna induces resistance to $C$. gloeosporioides in avocado fruits. Mol. Plant-Microbe Interact. 7:326-333.

29. Prusky, D., Hamdan, H., Ardi, R., and Keen, N. T. 1996. Induction of biosynthesis of the flavonoid epicatechin in avocado suspension cells treated with an enriched $\mathrm{CO}_{2}$ atmosphere. Physiol. Mol. Plant Pathol. 48:171-178.

30. Prusky, D., and Keen, N. T. 1993. Involvement of preformed antifungal compounds in the resistance of subtropical fruits to fungal decay. Plant Dis. 7:114-119.

31. Prusky, D., Keen, N. T., and Eaks, I. 1983. Further evidence for the involvement of a preformed antifungal compound in the latency of Colletotrichum gloeosporioides on the unripe fruits. Physiol. Mol. Plant Pathol. 22:189-198.

32. Prusky, D., Keen, N. T., Sims, J. J., and Midland, S. L. 1982. Possible involvement of an antifungal diene in the latency of Colletotrichum gloeosporioides on unripe avocado fruits. Phytopathology 72:15781582.

33. Prusky, D., Kobiler, I., and Jacoby, B. 1988. Involvement of epicatechin in cultivar susceptibility of avocado fruits to Colletotrichum gloeosporioides after harvest. Phytopathol. Z. 123:140-146.

34. Prusky, D., McEvoy, J. L., Leverentz, B., and Conway, L. S. 2001. Local modulation of host $\mathrm{pH}$ by Colletotrichum species as a mechanism to increase virulence. Mol. Plant-Microbe Interact. 14:1105-1113. 
35. Prusky, D., and Plumbley, R. A. 1992. Quiescent infection of Colletotrichum in tropical and subtropical fruits. Pages 289-307 in: Colletotrichum: Biology and Control. J. A. Baily and M. Jeger, eds. CAB International, Wallingford, UK.

36. Sambrook, J., Fritsch, E. F., and Maniatis, T. A. 1989. Molecular Cloning: A Laboratory Manual. 2nd ed. Cold Spring Harbor Laboratory, Cold Spring Harbor, NY.

37. Sbaghi, M., Jeandet, P., Bessis, R., and Leroux, P. 1996. Degradation of stilbene-type phytoalexins in relation to the pathogenicity of Botrytis cinerea to grapevines. Plant Pathol. 45:139-144.

38. Schouten, A., Wagemakers, L., Stefanato, F. L., van der Kaaij, R. M., and van Kan, J. A. L. 2002. Resveratrol acts as a natural profungicide and induces self-intoxication by a specific laccase. Mol. Microbiol. 43:883894.

39. Soden, D. M., and Dobson, A. D. 2001. Differential regulation of laccase gene expression in Pleurotus sajor-caju. Microbiology 147:1755-1763.

40. Thurston, C. F. 1994. The structure and function of fungal laccases. Microbiology 140:19-26.

41. Tu, J. C. 1985. An improved Mathur's medium for growth, sporulation and germination of conidia of Colletotrichum lindemuthianum. Microbiosis 44:87-93.
42. Van Etten, H., Matthews, D., and Matthews, P. 1989. Phytoalexin detoxification: Importance for pathogenicity and practical implications. Annu. Rev. Phytopathol. 27:143-164.

43. Wang, P., and Nuss, D. L. 1998. Identification of Cryphonectria parasitica laccase gene promoter element in cycloheximide-inducible, hypovirus-repressible transcriptional activation. Gene 210:79-84.

44. Wang, X., Kobiler, I., Lichter, A., Leikin-Frenkel, A., and Prusky, D. 2005. Enhanced expression of avfael encoding a long-chain fatty acid elongase during the induction of the antifungal diene in avocado fruits. Physiol. Mol. Plant Pathol. 65:171-180.

45. Wang, X., Lichter, A., Kobiler, I., Leikin-Frenkel, A., and Prusky, D. 2004. Expression of $\Delta^{12}$ fatty acid desaturase during the induced accumulation of the antifungal diene involved in resistance to $C$. gloeosporioides in avocado fruits. Mol. Plant Pathol. 5:575-585.

46. Williamson, P. R. 1994. Biochemical and molecular characterization of the diphenol oxidase of Cryptococcus neoformans: Identification as a laccase. J. Bacteriol. 176:656-664.

47. Yakoby, N., Kobiler, I., Dinoor, A., and Prusky, D. 2000. pH regulation of pectate lyase secretion modulates the attack of Colletotrichum gloeosporioides on avocado fruits. Appl. Environ. Microbiol. 66:10261030. 